\title{
Ensayos sobre el desorden La ciudad histórica
}

\author{
Xavier Rubert de Ventós
}

Extracto del texto original

(Ed. Kairós, 1976, ISBN 9788472450769)

DOI: 10.5821/palimpsesto.17.5382

\section{De la ciudad protagonista a la ciudad residuo}

La ciudad clásica, compendio y espejo de la sociedad en que se inscribía, parece haber perdido hoy su papel protagonista: de centro a la vez económico, político y cultural.

Desde la revolución industrial, el centro de la ciudad ya no es el eje de la producción -la fábrica se instala en la periferia, organizando la vivienda a su alrededor-, y en la llamada sociedad post-industrial entra a su vez en crisis su importancia como mercado: como lugar, en términos de Weber, «donde se produce un intercambio de bienes no ocasional sino regular». En una sociedad basada en la información, la presencia física y el intercambio de bienes en el mercado es cada vez menos decisiva. La función comunicativa del clásico mercado ciudadano ha sido en buena parte absorbida por los medios de información. (...) Tanto para la producción como para la distribución de bienes, la ciudad resulta un artefacto cada vez menos funcional.

Perdido su liderazgo económico, ¿no mantiene, sin embargo, el político?, ¿no sigue siendo el lugar del poder?

En efecto, la ciudad es aún el almacén de los grandes símbolos -Parlamentos y Bolsas, Catedrales y Bancos-, pero el contenido efectivo de estos símbolos no está ya ahí: las transacciones más significativas entre grandes empresas no cotizan ya en bolsa; los Parlamentos cada día parecen más coartadas de un ejecutivo directamente sintonizado con los altos intereses económicos o estratégicos, que sólo por decoro mantienen las «formas" de las instituciones liberales. L. Wirth había señalado que en la ciudad no siempre coinciden las "zonas administrativas" y las "zonas naturales» (...), pero hoy es la ciudad en su conjunto la que parece una inmensa uzona administrativam desplazada de pa czona naturale del poder y de las decisio la «zona natural del podory de las decisiones. La ciudad puede ser la sede más o menos circunstancial de este poder, pero no constituye ya su verdadero objetivo. Para las grandes organizaciones internacionales (...), las instituciones municipales o locales dejan de ser el centro de emanación o de atención del poder para entrar en el capítulo de los "gastos de representación» o de «inversión en imagen» (...). Queda pues en la ciudad la estratigrafía de los cascarones vacíos: de los monumentos del Estado Confesional, del Imperial, del Liberal..

La importancia cultural de la ciudad dependía a su vez de los dos factores anteriores: de su centralidad a un tiempo económica y política. Su trascendencia respecto de «un» orden y la capacidad de generar alternativas se basaba en la multiplicidad de códigos que en ella se acumulaban, solapaban, confundían y enfrentaban: profesionales y políticos, familiares y estamentales. En las márgenes y huecos de estas instancias -es decir en la libertad y el vacío que nace sólo de la proliferación de códigos y sistemas de pertenencia- surgió la ciencia y la bohemia, la imaginación artística y revolucionaria. En los rincones y costuras de una ciudad que era a la vez el lugar de la división del trabajo y del mercado, del poder político burgués y de las instituciones confesionales, del proteccionismo y del libre cambio, soplaba aquel «aire de la ciudad que hace libre» donde podía aún crecer y camuflarse la «anomalía» cultural.

Perdida su complejidad burguesa, la cultura ciudadana se transforma cada vez más en lo que había sido antes de la irrupción -en Atenas, en Florencia o en París- de una clase emprendedora e individualista. Vuelve a ser cultura de recintos, monástica o alejandrina: archivo, clasificación, escolástica, casta cultural especializada. Y como entonces, las auténticas alternativas culturales no provienen ya de los indígenas de la cultura sino que llegan de la periferia: de los nuevos de los nuevos bárbarc de los jovenes o de las mujeres. La innovación que en la ciudad liberal podía surgir de un contacto no codificado de antemano entre el dinero, el poder político y la cultura, no aparece ya en una ciudad que ha perdido su importancia y complejidad al tiempo que ha ganado en escala y se ha hecho simple instrumento del Estado o la Finanza. La ciudad deja de ser un espectáculo relativamente aleatorio y abierto al hacerse precisa y deliberadamente espectacular, es decir, promocionada y consumida ya como espectáculo con el que el poder trata de impresionar o distraer a sus bárbaros locales, a los suburbanos. (...)
Y frente a este centro-espectáculo, la cultura del suburbio residencial, del campus o la comuna, se hace coleccionismo y hágalo-usted-mismo. El amateurismo o bricolage de derechas y la contracultura de izquierdas, coinciden así en su rechazo de la ciudad. (...)

La ciudad burguesa era la figura de una geografía basada en la división del trabajo y las necesidades del mercado, pero que llegó a adquirir una autonomía y valor propios que hicieron de ella un fenómeno cultural, y no meramente económico. La ciudad no era el espacio abstracto de la producción y la explotación, sino también la arena de expresión e innovación: valor de uso además de valor de cambio.

Hoy la ciudad es el fondo («el espacio instrumental de reproducción de las relaciones de producción", Lefebvre) de un poder o una clase que puede estar en o incluso vivir de la ciudad, pero que no es ciudadana. Las burguesías ciudadanas establecieron una relación instrumental y unilateral con el campo -el campo como "granero» 0 «parque»-, de la que es ahora víctima la ciudad...Es la ciudad misma la que es hoy medio o instrumento, fondo o residuo de un sistema que genera un tejido urbano instrumental e indiferenciado.

Perdida su razón y función tradicionales, es lógico que perdiera también su encanto. El modelo que inspira hoy los romanticismos urbanos y los intentos de recuperar la calidad de la ciudad clásica es siempre la ciudad burguesa y cosmopolita. Pero ¿es posible reencontrar sus calidades sin recuperar su verdad histórica? (...)

\section{Los usos del residuo}

Dos reacciones son posibles frente a esta crisis ciudadana. La primera, atractiva por lo que tiene a la vez de coherente con el anterior diagnóstico y de iconoclasta respecto de la literatura urbanística convencional, concluye que debe abandonarse esta ciudad que ha perdido a la vez su sentido y su duende, su función y su encanto. Frente a la retórica del «corazón de la ciudad", de la «intensidad" y "creatividad" de la vida urbana, se considera la ciudad como un hecho arqueológico susceptible de ser estudiado, pero no ya recuperado.

«Es tiempo -argumenta en este sentido A. Touraine- ${ }^{-1}$ de abandonar la idea de que la ciudad es apertura y libertad porque es densa y concentrada. La fuerza que mantiene la ciudad metropolitana que conocemos se debe a que es el lugar de defensa de los intereses de antiguas clases dirigentes transformadas en clases medias celosas de sus privilegios. La ciudad ha perdido su función como instrumento de formación de una clase dirigente y como agente de modernización. Se está así volviendo el lugar de la segregación y la descomposición; no ya de la producción sino de la reproducción. ( ...). La ciudad con su centro ha dejado de ser el lugar de la apertura de posibilidades y se ha transformado en el lugar de la dominación. Ya no es más que el agrupamiento de todo lo dependiente: de la gente como consumidor o parado, de los que viven de la redistribución de las clases ricas (...). Lo que hay que cuestionar, lo que hay que suprimir, es pues el centro, la idea de que un conjunto debe tener un centro. La única actitud inteligente es combatir la ciudad, esforzándose ante todo en inventar una organización inversa del espacio no dominada por el par centro/periferia, sino por la coordinación de áreas y regiones."

La "coordinación de áreas y regiones», en efecto, es una organización espacial mucho más eficiente y acorde con las exigencias políticas de las tecnoestructuras y monopolios multinacionales. Parlamentos y ciudades eran formaciones adecuadas a la pluralidad de tendencias de una sociedad burguesa (...). Ejecutivos, poderes paralelos y áreas metropolitanas son las que responden a los nuevos detentadores del poder económico y decisorio.

Descentralización del espacio y las funciones desde luego, pero al servicio -y esto Touraine no lo señala- de la concentración del poder. ¿Acaso no beneficia al poder central la atomización de los hogares y la zonificación de las actividades que parece justificar técnicamente su dominación como necesidad de coordinación? Desde la cibernética hasta la ethología nos ofrecen sugestivos modelos de organización no centralizada ni jerárquica, que parecen legitimar una organización habitacional anti-urbana. Pero observamos pronto que los beneficios de estos sistemas pueden darse sólo en una "ciudad" y nunca en un «tejido urbano". (...)

El marco físico de un poder descentralizado parece pues un espacio de alta concentración, densidad y complejidad funcional, tal como se daba en las ciudades históricas. La sinergia y stimergia entre individuos o factores diversos pueden producir en ella cosas tan imposibles en una aldea como en una comuna contracultural, en un campus universitario como en un suburbio elegante. ¿Pero puede el centro de las ciudades seguir siendo el foco cosmopolita de riqueza y confluencia de estilos de vida cuando la complejidad real de la ciudad burguesa no existe ya, y su esqueleto es una realidad a la que no se «pertenece» sino que se "usa», como se usa una estación de servicio?

Perdida su trascendencia económica, el poder va abandonando los centros de la ciudad a su suerte. Entre los "containers" de oficinas o de centros de decisión, práticamente autónomos y convenientemente protegidos (...), las calzadas han sido adaptadas al tránsito rápido y las aceras a la no menos rápida degradación. Pero puede pensarse que precisamente en tanto que disfuncional desatendido y anacrónico, este espacio urbano puede seguir cobijando hoy algunas de las virtudes de la ciudad clásica. ¿No es acaso la desaparición, obsolescencia u olvido del uso de un artefacto -de una máscara, una imagen o un «ingenio»- lo que los transforma en obra abierta a un uso innovador o a un consumo artístico? ¿Y no será sólo en estos márgenes en los que ya ninguna institución se interesa en codificar y funcionalizar nuestra conducta donde podemos establecer aún relaciones no programadas; ejercer unas «libertades» que hoy son sólo posibles en la periferia de los centros de interés del poder?

Esta posibilidad era demasiado evidente para que un poder que tiende a la administración total de nuestra existencia no tomara -no haya empezado a tomar ya- cartas en el asunto. La supresión de un sector en que la gente pueda recuperar el gusto por la interacción aleatoria y el intercambio de información (....), podía no resultar inmediatamente rentable, pero era imprescindible a largo plazo. Y precisamente para el «acondicionamiento» de estos espacios relativamente abandonados por la especulación económica o la ingeniería técnica estaba la ingeniería social.

La generación de tejido urbano nuevo y la «regeneración» de los cascos antiguos siguen de este modo el principio que, según Foucault, ha regido la instalación de cárceles y aulas². Se trata de organizar un espacio físico y funcional en el que «normalizar» al ciudadano; en el que hacer de él una personalidad definida, circunscrita, repertoriada. Como la cárcel ha de transformar a los miembros del hampa en delincuentes «normales", las nuevas ciudades tenderán a hacer de la fauna cosmopolita de las ciudades clásicas, ciudadanos «normales», es decir, individuos perfectamente sincronizados con su profesión, ansiosos respecto de dus status y su futuro, realizándose mediante el consumo de bienes, cultura, información y demás servicios.

Es en este contexto donde debe situarse la apología del desorden de Richard Sennett ${ }^{3}$. Touraine concluía de todo ello que debe abandonarse el modelo de la ciudad clásica para buscar formaciones alternativas. Sennett sugiere, por el contrario, que existen nuevos usos posibles de este desorden. Un desorden, como acabamos de ver frágil y precario, y que la intervención pública tiende a regimentar transformando sus márgenes en pura violencia.

A. Touraine, Cartas a una estudiante. Ed. Kairós, 1977. M. Foucault, Surveller et punir. Naissance de la prison. Gallimard, París, 1975.

${ }^{3} \mathrm{R}$. Sennet, Identidad personal y vida urbana. Península, Barcelona, 1975

XAVIER RUBERT DE VENTÓS es Doctor en Filosofía por la UB y catedrático de la UPC. Ha enseñado en las universidades de Cincinnati, Harvard, Berkeley y Mexico entre otras, y es autor de una amplia obra sobre temas de moral, estética y sociología. 